\title{
School Interventions After the Joplin Tornado
}

\author{
Robert K. Kanter, MD; ${ }^{1,2}$ David Abramson, $\mathrm{PhD}, \mathrm{MPH}^{2}$
}

1. Pediatric Critical Care Medicine, SUNY Upstate Medical University, Syracuse, New York USA

2. National Center for Disaster Preparedness, Columbia University, New York, New York USA

\section{Correspondence:}

Robert K. Kanter, MD

Pediatric Critical Care Medicine

SUNY Upstate Medical University

750 E. Adams St.

Syracuse, NY 13210 USA

E-mail: kanterr@upstate.edu

Conflicts of interest: The authors report no conflicts of interest.

Keywords: behavioral health; disaster recovery; just-in-time training; resilience; school health; vulnerability

Received: July 31, 2013

Accepted: September 15, 2013

Online publication: March 21, 2014

doi:10.1017/S1049023X14000181

\begin{abstract}
Background/Objective: To qualitatively describe interventions by schools to meet children's needs after the May 2011 Joplin, Missouri tornado.

Methods: Qualitative exploratory study conducted six months after the tornado. Key informant interviews with school staff (teachers, psychologists, guidance counselor, nurse, principal), public health official, and physicians.

Report: After the tornado, school staff immediately worked to contact every enrolled child to provide assistance and coordinate recovery services. Despite severe damage to half of the city's schools, the decision was made to reopen schools at the earliest possible time to provide a safe, reassuring environment and additional services. An expanded summer school session emphasized child safety and emotional wellbeing. The 2011-2012 school year began on time, less than three months after the disaster, using temporary facilities. Displaced children were bused to their usual schools regardless of their new temporary residence locations. In just-in-time training sessions, teachers developed strategies to support students and staff experiencing anxiety or depression. Certified counselors conducted school-based, small-group counseling for students. Selective referrals were made to community mental health providers for children with greatest needs.

Conclusions: Evidence from Joplin adds to a small body of empirical experience demonstrating the important contribution of schools to postdisaster community recovery. Despite timely and proactive services, many families and children struggled after the tornado. Improvements in the effectiveness of postdisaster interventions at schools will follow from future scientific evidence on optimal approaches.
\end{abstract}

Kanter RK, Abramson D. School interventions after the Joplin tornado. Prehosp Disaster Med. 2014;29(2):214-217.

\section{Introduction}

Schools are a large part of a child's normal everyday environment. School activities and services necessary for education also can promote children's health and safety. Traumatic experiences in disasters are expected to cause stress and exacerbate mental health disorders. Cognitive, emotional, physical, and behavioral effects last weeks for some, and years for others. ${ }^{1-7}$ Schools may play an important role in promoting children's mental and behavioral health after disasters. ${ }^{8,9}$ Previous empirical reports have evaluated postdisaster plans for school counseling or mental health referral ${ }^{10}$ and also have evaluated particular school-based, therapeutic techniques. ${ }^{11-15}$ However, few published accounts describe postdisaster school interventions as a component of community wide disaster recovery. The present community case study describes such efforts in Joplin, Missouri after the May 2011 tornado.

\begin{abstract}
Methods
Setting

Joplin is a community of 50,150 in southwestern Missouri (USA). ${ }^{16}$ In the late afternoon of Sunday, May 22, 2011, an Enhanced Fujita Scale (EF) 5 tornado severely damaged and/or totally destroyed an area nearly a mile wide across the entire community. One hundred sixty two died in an area directly affecting 18,000 (mortality rate in severe damage zone $=9 / 1000$ ). Approximately 1,000 people were injured. Children 18 years and younger accounted for $14(9 \%)$ of the deaths. Nine thousand housing units, nine of the city's 18 schools, and one of the community's two hospitals were severely damaged. ${ }^{17,18}$

The tornado occurred at the end of the 2010-2011 school year. Interviews for this study were conducted six months after the storm, during the temporary restoration phase of community disaster recovery. ${ }^{19,20}$ Most essential services and functions had been
\end{abstract}


restored, but many continued to operate in temporary or partiallyrepaired facilities. At the time of the interviews for this study, over 500 displaced households were still living in temporary housing, including more than 300 modular homes ${ }^{21}$ or shared residences.

\section{Case Study}

Qualitative observations were obtained in an exploratory study on the basis of face-to-face interviews with 14 key informants conducted by one of the authors (RK) in Joplin during December 2011. For this exploratory study, informants were selected as a convenience sample of professionals, identified by a health care provider in Joplin. Informants consisted of professionals providing a broad range of services to children, with an emphasis on school services. They included school staff (teachers, psychologists, a guidance counselor, a school nurse, a school principal) from both public and parochial schools, a city public health official, and physicians (pediatrician, family medicine, emergency medicine). Semistructured interviews began with open-ended questions regarding the effects of the tornado on children's health and services, and school interventions after the disaster (see Table 1). Clarifying details and examples were sought. Written notes were made during the interviews. Interviews were recorded with consent of the informants. Notes and recordings were qualitatively analyzed to identify themes pertaining to children's needs and school services. This study of professionals' roles and observations was considered exempt from review by the Institutional Review Board for the Protection of Human Subjects at SUNY Upstate Medical University.

\section{Report}

Summer 2011 Interventions

Despite severe damage to half of the community's school facilities, public school district leaders decided within one day after the disaster to resume school services at the earliest possible time. This was intended to provide a safe and reassuring environment, to rapidly identify children's needs, and to promote coordination of services. Restoration of services included an expanded summer school enrollment serving more than the usual number of children, with an expanded schedule lasting eight weeks instead of the usual four weeks. The summer school session emphasized attention to children's safety and emotional wellbeing rather than academic progress.

For the same reasons, a decision was also quickly made to reopen school as scheduled, on August 17th for the 2011-2012 academic year. This required rapidly arranging temporary facilities to replace half of the district's buildings, supplies, and equipment in less than three months. Temporary facilities were rented and modular structures were utilized. In order to normalize children's return for the 2011-2012 academic year, it also was decided that displaced children would be offered re-enrollment at their usual schools, regardless of their temporary residence locations in or outside of the community. Public busing would be provided to facilitate children's attendance at their usual schools, regardless of where their families had obtained temporary lodging.

Within the first day after the storm, school district staff began a sustained effort to locate and contact every child and staff member associated with the school system. This was intended to offer assistance to those who needed it, and to obtain contact information necessary to coordinate subsequent school activities. The search for displaced individuals included walks through neighborhoods and informal contacts through social networks.

\begin{tabular}{|l|l|}
\hline $\begin{array}{l}\text { Open-Ended, Initial } \\
\text { Questions }\end{array}$ & $\begin{array}{l}\text { Probing Questions for Additional } \\
\text { Details }\end{array}$ \\
\hline $\begin{array}{c}\text { Children's health needs } \\
\text { that differ from usual? }\end{array}$ & $\begin{array}{l}\text {-Acute illnesses } \\
\text {-Anxiety } \\
\text {-Depression } \\
\text {-Domestic violence } \\
\text {-Drug and alcohol use }\end{array}$ \\
\hline How are the health needs & $\begin{array}{l}\text {-Visit to physician } \\
\text {-Visit to emergency department } \\
\text {-Hospitalization }\end{array}$ \\
\hline -School absence \\
-School observations
\end{tabular}

Table 1. Interview Questions

Some students, using social media, proved more effective at locating displaced persons than formal efforts of school administrators and staff. An informant reported that one high school student provided contact information for 60 classmates identified via the social media site, Facebook. Although telephone communications were initially out of service, later phone contacts throughout the summer were successful in identifying needs and coordinating plans.

Staff training began during the summer for public and private school teachers on techniques for reassurance, practical classroom mental health interventions, and the recognition of more severe disorders needing professional treatment. Some training sessions were taught by psychiatry staff from the University of Missouri School of Medicine. Also developed during the summer were formal interventions in which licensed mental health counselors were hired to provide regular, small-group counseling at public schools for students needing support throughout the next school year.

In addition, school staff members were provided with guidance about care for themselves and colleagues in the disaster aftermath. "Buddy system" supports were developed for teachers. Every teacher was paired with another for emotional support, as well as to provide coverage for each other. This allowed for the numerous personal logistical tasks necessary in the months after the disaster. 
Students were provided with school supplies and high school students were given laptop computers. Numerous grants were available rapidly from federal, state, and local public agencies as well as private funders supporting mental health and community recovery efforts.

In order to mark losses and new beginnings, some schools conducted celebrations and memorials for lost members of the school, and to say goodbye to demolished school facilities.

\section{Autumn 2011 School Session Interventions}

Although more than $30 \%$ of Joplin residents had been displaced, few left the community. As a result of aggressive efforts at student re-enrollment, public school attendance had declined by less than $10 \%$ on opening day.

At the start of the academic year, public school psychologists sent a questionnaire home with every student asking parents to state concerns and requests for assistance. Parent surveys identified children for participation in the small-group counseling sessions at public schools, as well as other individual needs. As a result of these efforts, as many as $25 \%$ of students at some schools were participating in the small-group sessions during December 2011. For small numbers of children needing more individualized attention, school counselors provided evaluations and referral to mental health providers in the community.

At the beginning of the school year, teachers conducted classroom exercises intended to relax students and promote a calm and safe environment. Disaster drills were conducted to reassure students about improved procedures and reinforced shelters designed to better withstand tornado damage. Teachers found that some children wanted to talk frequently and repeatedly during class time about traumatic events they had witnessed, and losses they had suffered. Difficulty was encountered when some children wanted to dwell on painful memories and others wanted to avoid these topics. At parochial schools, teachers reported that the faith-based setting provided a favorable context for the discussion of losses.

Many informants noted a greater community-wide acceptance of mental health services after the storm than previously. Most of the school staff informants believed the school-based mental health interventions had been helpful to students, their families, and staff. However, no quantitative or comparative data were available to evaluate the effectiveness of interventions.

\section{Mental and Behavioral Health Observations}

Most school staff informants at both public and parochial schools reported that children's postdisaster behavior tended to be more aggressive and irritable than usual. Teachers attributed disruptive behavior to the temporary crowded school facility, as well as stress. Almost all school and health care informants reported a community-wide increase in mental and behavioral health issues such as anxiety, depression, sleep disorders, domestic violence, drug and alcohol abuse, teen pregnancies, and suicide attempts. For a small number of students, school performance seemed to suffer as a result of anxiety.

Informants noted the following tendencies: elementary school children tended to act out with aggressive behavior; middle school students tended to verbalize openly their concerns with school staff; and high school students with serious emotional issues tended to become withdrawn. Several informants suggested that adults and adolescents appeared to be having more severe consequences from postdisaster disorders than younger children.
Postdisaster vulnerability to mental and behavioral disorders appeared to be greatest for those children who had problems with social coping prior to the tornado. Children whose parents were coping well after the storm seemed to be most resilient.

Many informants suggested that children displaced by the storm did not seem to be coping any differently than those who remained in their own homes. Keeping displaced children in their usual schools may have mitigated some of the adverse effects of their displacement. Several informants suggested that for some children, emotional stresses after the tornado were not greater than the substantial stresses they faced on a frequent basis prior to the storm.

\section{Other Health Problems}

Other minor and transient pediatric health problems were noted by several informants, including nonspecific, mild respiratory symptoms, but these resolved within the first few weeks after the storm. A physician and a public health official reported that screening had identified some children with blood lead levels in an elevated range, higher than typical for the community. Ongoing surveillance is in progress to determine the potential environmental sources of postdisaster lead exposure and possible consequences.

\section{Ongoing Problems and Concerns}

Most of the funding for postdisaster counseling was limited to one year. Many school staff and health care providers anticipated mental health needs for some children lasting beyond the funding period. Informants perceived large differences in funding, with disaster recovery support at public schools greatly exceeding resources available at parochial schools.

Many informants noted that laws protecting confidentiality prevented direct communication between school staff and health care providers. All such communications to coordinate care had to be mediated through families.

\section{Discussion}

Important postdisaster school interventions included rapid reopening to provide and coordinate services; rapidly contacting displaced families; involvement of experts to promote mental health; just-in-time training of staff; and selective referral of children to community providers when needs exceed school based capabilities. Proactive decisions were consistent with recommendations of the National Commission on Children and Disasters (Section 7.3). ${ }^{8}$ The observed utility of social media in postdisaster communications reinforces recent reports. ${ }^{22}$

The observation that vulnerability of children to postdisaster behavioral and mental health problems parallels their prior vulnerability is consistent with previous evidence. ${ }^{4}$ Although disaster exposures at the greatest level of severity may outweigh baseline vulnerability or resilience as a determinant of postdisaster mental and behavioral health problems, ${ }^{7}$ informants were not able to comment on this tendency. Likewise, informants were not able to report associations between children's socioeconomic status and mental health or behavioral observations, although socioeconomic status has been observed previously as a determinant of baseline and postdisaster mental and behavioral health. ${ }^{4,5,7}$

Information provided about mental and behavioral health interventions in the Joplin schools adds to a small body of empirical experience on postdisaster school mental health services in the Gulf Coast after Hurricanes Katrina and Rita ${ }^{23,24}$ and after 
the Oklahoma City terrorist bombing of $1995 .^{25}$ Each report describes services qualitatively, on the basis of participants' and key informants' observations. Rapid normalization of students' environments was achieved by facilitating early school enrollment in Joplin and the Gulf Coast. School enrollment was less of an issue in Oklahoma City where fewer were displaced. Just-in-time school staff orientation was important in all these communities. Public acceptance of mental health services appears to have been more consistent in Joplin than in the earlier reports. Circumstances in Joplin and Oklahoma City were similar in that school staff, children, and families all shared similar experiences and generally remained in the same community. In contrast, communities studied in the Gulf Coast were less directly affected by the hurricanes, but provided temporary housing for displaced families arriving from distant locations. This report of the Joplin experience is limited to an earlier phase of community restoration than the other studies. Outside financial assistance seems to have been available more rapidly and at higher funding levels for Joplin than in previous experiences. Concerns were voiced in Joplin, the Gulf Coast, and Oklahoma City that mental health needs were likely to persist after temporary funding expired.

The present exploratory study was not designed to quantitatively evaluate outcomes or compare the effectiveness of Joplin's approach with others. Generalizing observations from one setting is limited by the circumstances unique to each community and each public health emergency. Since informants were not selected in a way that

\section{References}

1. Coping with a traumatic event. Centers for Disease Control and Prevention. Atlanta, GA, 2005. http://www.bt.cdc.gov/masscasualties/copingpro.asp. Accessed February 17, 2012.

2. Hagan JF and the American Academy of Pediatrics Committee on Psychosocial aspects of Child and Family Health, and the Task Force on Terrorism. Psychosocial implications of disaster or terrorism on children: a guide for the pediatrician. Pediatrics. 2005;116(3):787-795.

3. DiMaggio C, Galea S, Richardson LD. Emergency department visits for behavioral and mental health care after a terrorist attack. Ann Emerg Med. 2007; 50(3):327-334

4. Abramson D, Park YS, Stehling-Ariza T, Redlener I. Children as bellwethers of recovery: dysfunctional systems and the effects of parents, households, and neighborhoods on serious emotional disturbance in children after Hurricane Katrina. Disaster Med Public Health Preparedness. 2010;4(Supp 1):S17-S27.

5. Abramson D, Redlener I, Stehling-Ariza T, et al. Impact on children and families of the Deepwater Horizon oil spill. National Center for Disaster Preparedness, Research Brief 2010:8. Columbia University Mailman School of Public Health, NY USA, 2010.

6. Yun K, Lurie N, Hyde PS. Moving mental health into the disaster-preparedness spotlight. N Engl J Med. 2010;363(13):1193-1195.

7. McLaughlin KA, Fairbank JA, Gruber MJ, et al. Trends in serious emotional disturbance among youths exposed to Hurricane Katrina. J Am Acad Child Adolesc Psychiatry. 2012;49(10):990-1000.

8. National Commission on Children and Disasters. 2010 Report to the President and Congress. AHRQPublication No. 10-M037. Rockville, MD: Agency for Healthcare Research and Quality. October 2010.

9. Lazarus PJ, Jimerson SR, Brock SE. Helping children after a natural disaster: information for parents and teachers. National Association of School Psychologists, Bethesda, MD. 2993. www.nasponline.org/resources/crisis_safety/naturaldisaster_ ho.aspx. Accessed February 17, 2012.

10. Graham J, Shirm S, Liggin R, et al. Mass-casualty events at schools: a national preparedness survey. Pediatrics. 2006;117(1):8-15.

11. Chemtob CM, Nakashima JP, Hamada RS. Psychosocial intervention for postdisaster trauma symptoms in elementary school children: a controlled community field study. Arch Pediatr Adolesc Med. 2002;156(3):211-216. ensured a representative sample, biases in their observations cannot be excluded. A more rigorous evaluation of postdisaster mental and behavioral school health interventions will have to account for a multiplicity of variables, including baseline characteristics of individuals, the severity and duration of their stress exposure, ${ }^{4,7}$ as well as controlled comparisons of specific therapeutic approaches.

As community-based institutions, schools serve as economic cornerstones for a large workforce of teachers, administrators, and support staff. Schools provide an essential function of child protection while parents address numerous postdisaster concerns. Moreover, community-wide school decisions, such as Joplin's determination to rapidly reopen their schools after the tornado, create independent recovery milestones that can be readily embraced by local residents and also contribute to a community's engagement in its own recovery.

\section{Conclusion}

Schools can provide safe environments for students and staff to express and address mental health issues after disasters. Timely and ongoing funding is necessary to enable such services.

\section{Acknowledgment}

The authors thank Fred Wheeler, DO, Joplin, Missouri, for providing extensive observations about Joplin's disaster recovery, as well as his invaluable assistance in identifying other informants essential to conducting this study.

12. Goenjian AK, Walling D, Steinberg AM, et al. A prospective study of posttraumatic stress and depressive reactions among treated and untreated adolescents 5 years after a catastrophic disaster. Am J Psychiatry. 2005;162(12):2302-2308.

13. Jaycox LH, Cohen JA, Mannarino AP, et al. Children's mental health care following Hurricane Katrina: a field trial of trauma-focused psychotherapies. J Trauma Stress. 2010;23(2):223-231.

14. Wolmer L, Hamiel D, Laor N. Preventing children's posttraumatic stress after disaster with teacher-based intervention: a controlled study. J Am Acad Child Adolesc Psychiatry. 2011;50(4):340-348.

15. Salloum A, Overstreet S. Grief and trauma intervention for children after disaster: exploring coping skills versus trauma narration. Behav Res Ther. 2012;50(3):169-179.

16. State and county QuickFacts: Joplin (city), Missouri. US Census Bureau. Washington DC, 2010. http://quickfacts.census.gov/qfd/states/29/2937592.html. Accessed February 17, 2012.

17. Sterling S. Joplin leader reviews tornado. Daily Star-Journal. Warrensburg, MO, October 2, 2011. http://dailystarjournal.com. Accessed February 17, 2012.

18. Anonymous. List of known dead after Joplin tornado. Springfield News-Leader, Springfield, Missouri USA June 2, 2011. www.news-leader.com. Accessed January 24, 2012.

19. Kates RW, Colten CE, Laska, Leatherman SP. Reconstruction of New Orleans after hurricane Katrina: a research perspective. PNAS. 2006;103(40):14653-14660.

20. Alesch DJ, Arendt LA, Holly JN. Managing for Long-Term Community Recovery in the Aftermath of Disaster. Public Entity Risk Institute, Fairfax, Virginia USA, 2009.

21. Stefanoni AB, Woodin D. FEMA villages called county's "fourth largest city". Joplin Globe, Joplin, MO. November 19, 2011. http://www.joplinglobe.com. Accessed February 17, 2012.

22. Merchant RM, Elmer S, Lurie N. Integrating social media into emergency preparedness efforts. $N$ Engl J Med. 2011;365(4):289-291.

23. Jaycox LH, Tanielian TL, Sharma P, et al. Schools' mental health responses after Hurricanes Katrina and Rita. Psychiatric Services. 2007;58(10):1339-1343.

24. Madrid PA, Garfield R, Jaberi P, et al. Mental health services in Louisiana school based health centers post-hurricanes Katrina and Rita. Professional Psychology. 2008;39:45-51.

25. Pfefferbaum B, Call JA, Sconzo GM. Mental health services for children in the first two years after the 1995 Oklahoma City terrorist bombing. Psychiatric Services. 1999;50(7):956-958. 